\title{
Homozygosity for the c.917A $\rightarrow T$ (p.N306l) Polymorphism in the EVER2/TMC8 Gene of Two Sisters with Epidermodysplasia Verruciformis Lewandowsky-Lutz Originally Described by Wilhelm Lutz
}

\author{
Andreas W. Arnold ${ }^{a}$ Bettina Burger ${ }^{b}$ Erwin Kump ${ }^{b} \quad$ Alexander Rufle $^{c}$ \\ Stephen K. Tyring ${ }^{f}$ Werner Kempf ${ }^{d, e}$ Peter Häusermann ${ }^{a}$ Peter H. Itin ${ }^{a}$ \\ Departments of a Dermatology, ${ }^{b}$ Biomedicine and ${ }^{c}$ Pathology, University Hospital Basel, Basel, and ${ }^{d}$ Department \\ of Dermatology, University Hospital Zurich, and ${ }^{\mathrm{e} K e m p f}$ und Pfaltz Histological Diagnostik, Research Unit, Zurich, \\ Switzerland; ' Department of Dermatology, Health Science Center, University of Texas, Houston, Tex., USA
}

\section{Key Words}

Epidermodysplasia - Lewandowsky-Lutz dysplasia - EVER • TMC $\cdot$ Human papillomavirus - Carcinogenesis $\cdot$ Gene $\cdot$ Genodermatosis

\footnotetext{
Abstract

Background: Epidermodysplasia verruciformis Lewandowsky-Lutz (EV) is a rare genodermatosis, characterised by development of numerous verrucous skin lesions caused by specific genotypes of human papillomaviruses belonging to the $\beta$-papillomavirus genus. The EV loci were mapped to chromosome 2p21-p24 (EV2) and 17q25 (EV1). On chromosome 17, 2 adjacent related genes - EVER1/TMC6 and EVER2/ $T M C 8$ - were identified. We reinvestigated 2 patients originally described by Wilhelm Lutz in 1946 with the aim to document the natural course of the disease and confirm his diagnosis. Methods: PCR fragments specific for exons with short flanking intron sequences of EVER1/TMC6 and EVER2/ TMC8 genes from patients' DNA were amplified using sequence information. The single-nucleotide polymorphism (SNP) rs7208422 was studied, using restriction fragment
}

length polymorphism analysis. Results: In the index patient, we identified a homozygous TT genotype in exon 8 of the EVER2/TMC8 gene (c.917A $\rightarrow \mathrm{T}$, p.N306I). The same mutation could thereafter be detected in her sister from paraffin-embedded skin. Conclusion: We have followed one of the first patients described with EV in Basel, Switzerland, in 1930 until today and demonstrated the TT genotype (SNP rs7208422) in the EVER2/TMC8 gene in this index patient and her sister. The results underline the possible relevance of SNP rs 7208422 by influencing the susceptibility to $\beta$-papillomaviruses and their oncogenic potential.

Copyright $\odot 2010$ S. Karger AG, Basel

\section{Introduction}

Epidermodysplasia verruciformis Lewandowsky-Lutz $(\mathrm{EV})$ is a rare genodermatosis characterised by development of verruciform skin lesions caused by specific genotypes of human papillomaviruses (HPV) of the $\beta$-papillomavirus $(\beta-\mathrm{HPV})$ genus [1]. Patients are at high risk of developing carcinoma in situ and spinocellular carcino-

\section{KARGER \\ Fax +4161306 1234 \\ E-Mail karger@karger.ch}

www.karger.com
C) 2010 S. Karger AG, Basel

$1018-8665 / 11 / 2221-0081 \$ 38.00 / 0$

Accessible online at:

www.karger.com/drm
Andreas W. Arnold

Dermatologie, Universitätsspital Basel

Petersgraben 4

$\mathrm{CH}-4031$ Basel (Switzerland)

E-Mail aarnold@uhbs.ch 


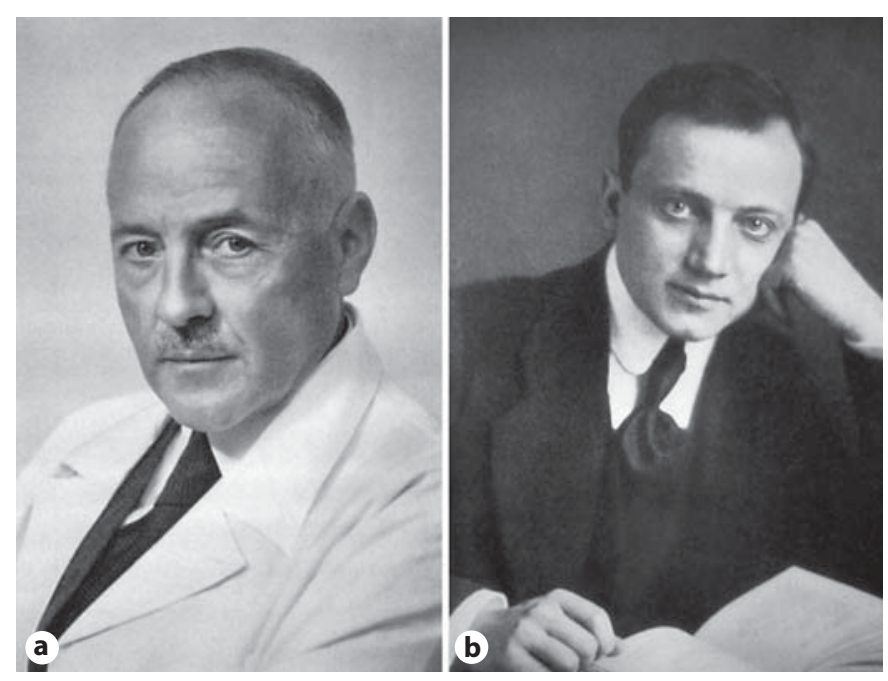

Fig. 1. a Wilhelm Lutz. b Felix Lewandowsky.

ma in UV light-exposed areas. At least $19 \beta$-HPV genotypes have been found in EV patients. HPV type 5 is usually, and type 8 occasionally, cited with malignant conversion [2]. About $70 \%$ of patients with cancers have antibodies to HPV-5 oncoproteins E6 or E7 (early protein 6 or 7) [2]. The molecular mechanism of the E6 and E7 proteins in causing skin cancer is not well understood. The viral E6 protein effectively blocks the epidermal apoptotic response to UV light and seems to play a role in promoting tumour development in cooperation with the mutagenic effects of UV [3]. Mutations of the p53 gene in EV patients by UV light and an abnormal expression of the $\mathrm{p} 53$ protein have been found to be associated with tumour progression. Therefore a syncarcinogenic effect of UV and $\beta$-HPV has been postulated. The finding that $10 \%$ of patients have consanguineous parents and $10 \%$ of EV families have more than 1 descendant affected suggests a genetic background may play a role. In general, EV shows an autosomal recessive pattern of inheritance (OMIM 226400) [4]. The EV loci were mapped to chromosome 2p21-p24 (EV2) and 17q25 (EV1) [5], respectively. In the EV1 interval, 2 adjacent related genes, EVER1 and EVER2, were identified in 2002 [6]. EVER proteins are members of the transmembrane channel-like (TMC) family. They are encoded by 8 genes (TMC1-8) $[7,8]$. EVER 1 and EVER 2 correspond to TMC6 and TMC8, respectively. They are involved in the intracellular zinc metabolism $[9,10]$.

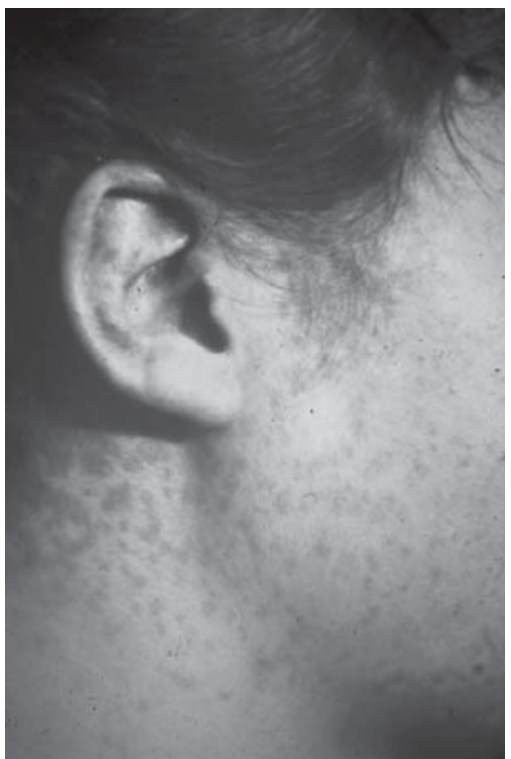

Fig. 2. Patient K.T. in 1929 with verrucous macules on the face and neck. Photograph by Wilhelm Lutz.

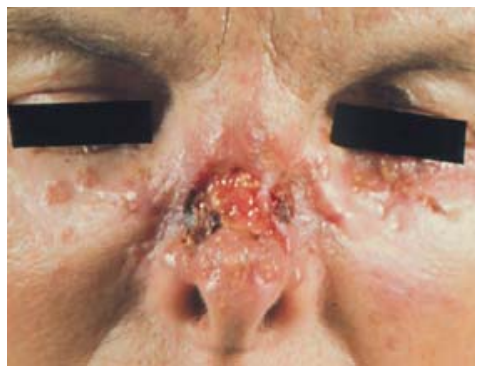

Fig. 3. Patient K.T. with spinocellular carcinoma of the nose and multiple actinic keratoses in 1976.

\section{Patients and Methods}

EV was first described in Basel in 1922 by the dermatologists Felix Lewandowsky and Wilhelm Lutz (fig. 1) [11]. They described a 29-year-old woman with 2 spinocellular carcinomas on her front and multiple reddish squamous papules, which resembled plane warts. Therefore, the authors called this disease 'epidermodysplasia verruciformis'. A second patient with EV originating from Basel was seen in the same year by the dermatologist Heinrich Fuchs [12].

In 1946, Wilhelm Lutz published on 2 sisters which he had seen in 1929 and 1930 with the same disease [13]. The older of them (named K.T.), born in 1912, showed verruca plana-like lesions on her neck, face and dorsal hands [14] (fig. 2). After 1947 she developed several actinic keratoses and spinocellular carcinomas (fig. 3). She died in 1983 after operation, and radiation, methotrexate and bleomycin therapy of several spinocellular carcinomas with metastases in regional lymph nodes [14] (fig. 4). A delay 


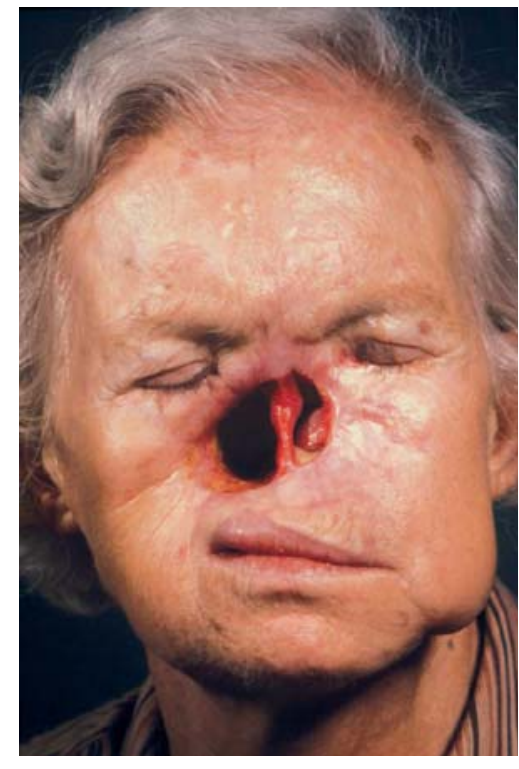

Fig. 4. Patient K.T. in 1982, shortly before she died.

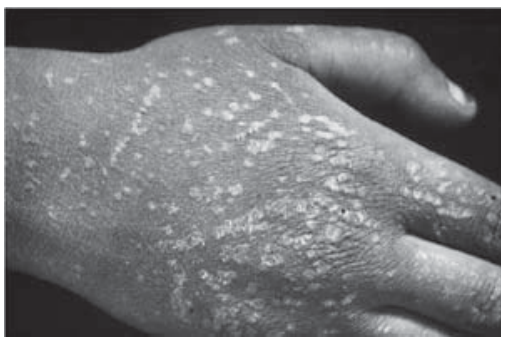

Fig. 6. Typical verrucous lesions of index patient L.H. in 1936. Photograph by Wilhelm Lutz.

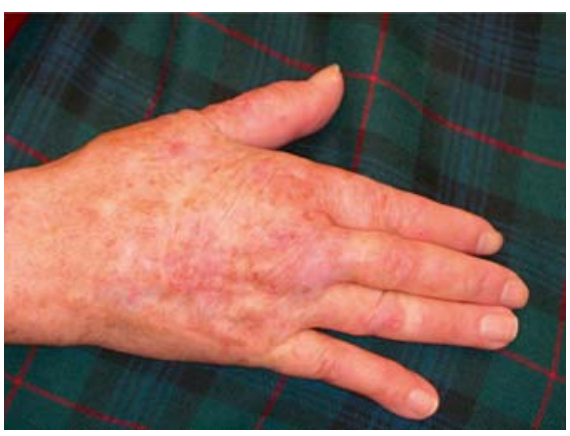

Fig. 9. Hand of index patient L.H. almost free of lesions in 2009.

Polymorphism in EVER2/TMC8 and Epidermodysplasia Verruciformis

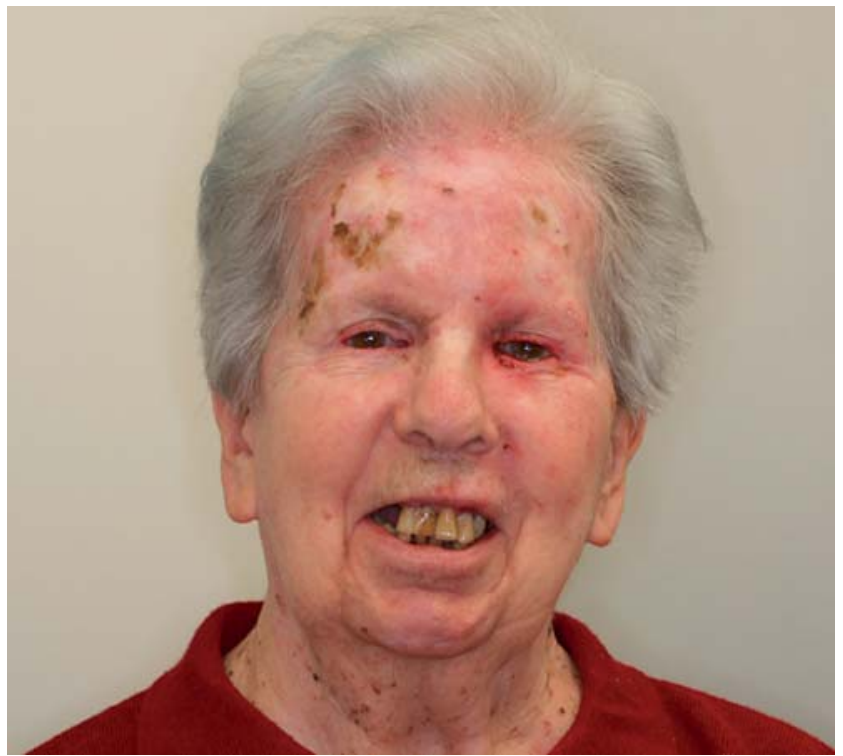

Fig. 5. Face of the index patient L.H. in 2009.
7

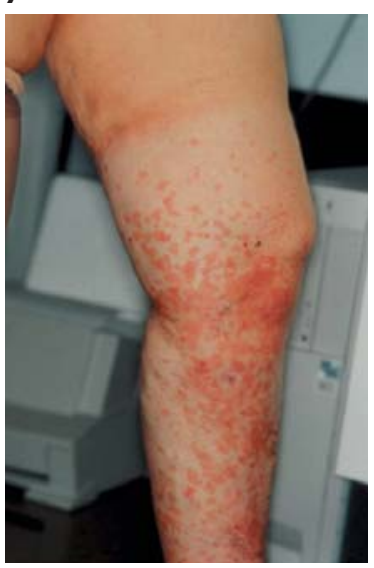

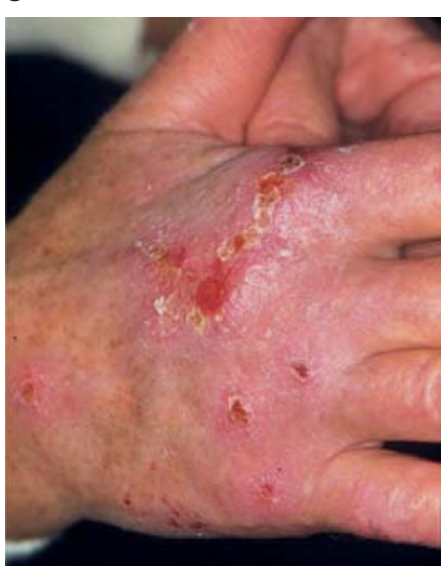

Fig. 7. Typical verruca plana-like lesions on the lower legs of index patient L.H. in 1982.

Fig. 8. Actinic keratosis and morbus Bowen in index patient L.H. in 1982 .

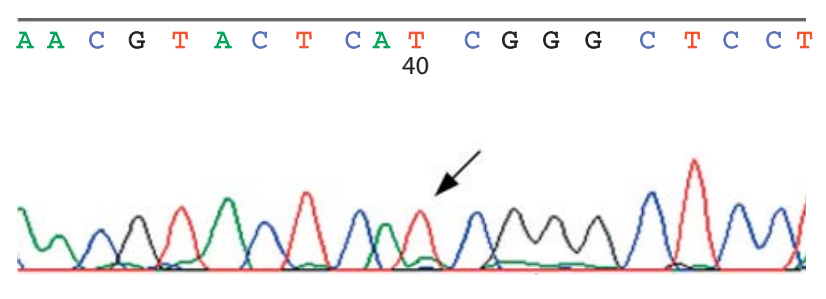

Fig. 10. Homozygous missense mutation in exon 8 of TMC 8 $($ c.917A $\rightarrow$ T) of patient K.T. leading to an amino acid exchange (p.N306I). 
in therapy of several years after the first diagnosis of spinocellular carcinoma in 1957 was caused by applying Iscador therapy in accordance with the wish of the patient.

The sister of K.T. (named L.H.), born in 1923, is still regularly controlled every 6 weeks in our clinic and the course is favourable (fig. 5). Since early childhood she has suffered from erythematous macules with a slight scaly appearance, mainly on her neck and hands (fig. 6) [13]. The parents of the 2 sisters were not consanguineous. L.H. has 1 healthy daughter, K.T. had no children. In 1946, Wilhelm Lutz published on the successful autoinoculation of the verruciform lesions in our patient L.H. and postulated that EV is not only a genetic abnormality [13]. Jablonska and Milewski [15] confirmed this hypothesis in their experiments in 1957. Since 1943 L.H. has developed brownish macules resembling pityriasis versicolor on her lower legs (fig. 7) [14]. Since 1975 several actinic keratoses, spinocellular carcinomas and basal cell carcinomas have been detected in sun-exposed areas, mainly in the face and on the scalp. The treatment included cryosurgery, surgery, photodynamic therapy, $\mathrm{CO}_{2}$ laser, topic 5-fluorouracil and imiquimod (fig. 8, 9). According to our experience, imiquimod cream is the best option for actinic keratosis in patients with EV. This treatment has been reported in a recent publication [16]. The favourable activity of imiquimod is probably due to its antiviral activity and suggests a viral genesis of the lesions.

In 2009 we detected HPV-5 in a spinocellular carcinoma. Sections of the specimens were used for HE staining and DNA preparation. Three consecutive $10-\mu \mathrm{m}$ paraffin sections from each specimen were used for DNA extraction. After deparaffinisation, all tissues were subjected to proteinase $\mathrm{K}$ digestion in lysis buffer (50 mM Tris- $\mathrm{HCl}, \mathrm{pH} 8.5,1 \mathrm{mM}$ EDTA, $0.5 \%$ Tween 20 ) at $53^{\circ} \mathrm{C}$ overnight. DNA was purified using the QIAamp DNA Mini Kit (Qiagen, Hilden, Germany) and was directly used for PCR. DNA quality was checked by amplification of the $\beta$-globin gene sequence using the GH20 (5'-GAAGAGCCAAGGACAGGTAC-3') and PC04 (5'-CAACTTCATCCACGTTCACC-3') primer sets [17]. Amplifiable DNA was recovered from all tissue samples. For HPV detection we used 4 different protocols as described elsewhere: (1) a nested PCR with the outer primer set MY09/MY11 and the internal nested primer set GP1/GP2 [17], (2) a nested PCR with the same outer primer pair MY09/MY11 and the internal nested primer pair GP5/GP6 [18], (3) a PCR with the L1C1/L1C2-1 primer set [18], and (4) a nested PCR protocol to preferentially detect $\beta$-HPV types, using the outer primer set CP62/CP69 and the internal nested primer set CP65/CP68 [19]. PCR was performed with genomic DNA, using 40 cycles for each primer set with the FastStart Taq Polymerase (Roche, Basel, Switzerland) in a total volume of $50 \mu \mathrm{l}$. All assays included positive and negative controls. Genomic DNA from an HPV-5-containing wart was used as a positive control. Water instead of DNA template and normal skin templates were used for negative PCR controls. In particular, DNA and PCR mixtures were prepared and stored in separate rooms, and positive controls were always separated from the test samples and reagents. The PCR products were detected by ethidium bromide staining after electrophoretic migration through $1.5 \%$ agarose gels.

Amplified HPV PCR products were purified prior to sequencing, using a High Pure PCR Product Purification Kit (Roche) according to the manufacturer's protocol. PCR products were submitted to automated sequencing in a Roche FLX genome sequencer (Microsynth, Balgach, Switzerland). The resulting DNA sequences were aligned against the reference sequences from the National Center for Biotechnology Information (NCBI) Entrez
Nucleotide database using the NCBI BLAST programme. The Nucleotide BLAST database was searched to determine the degree of homology to known HPV subtypes.

The EV genes were examined as follows. Genomic DNA of L.H. was extracted from peripheral blood lymphocytes after having obtained informed consent according to the guidelines of the Ethical Committee of Basel. PCR amplification (Qiagen, Valencia, Calif., USA) was performed by means of primers covering the entire coding sequence of the EVER1/TMC6 and EVER2/TMC8 genes as well as flanking intronic regions, using sequence information as described earlier [6]. Additional sequence information on primers and gene maps was kindly provided by Gerard Orth and Michel Favre (Department of Virology, Institute Pasteur, Paris, France). Purified PCR products were subjected (QIAquick Gel Extraction Kit; Qiagen) to bidirectional sequencing using the BigDye Terminator Kit (version 3.1) and ABI Prism 377 sequencer (PE Applied Biosystems, Foster City, Calif., USA).

The obtained results were subjected to computer-assisted alignment (BLAST NCBI) utilising sequence information deposited in NCBI GenBank. By using these genetic analyses, a truncating loss-of-function mutation in the EVER1/TMC6 or EVER2/ TMC8 gene could not be detected in the patient. The SNP rs7208422 revealed a homozygous mutated genotype in exon 8 of the EVER2/TMC8 gene (c.917A $\rightarrow$ T) leading to an amino acid change (p.N306I), which may be a risk factor for susceptibility to $\beta-\mathrm{HPV}$ infection and carcinogenesis [20, 21]. A further SNP (rs2748427) in EVER1/TMC6 showed a heterozygous mutation (c.373T $\rightarrow$ C; p.W125R). From patient K.T., genomic DNA was isolated from paraffin-embedded tissue by using the QIAamp DNA Mini Kit (Qiagen) according to the manufacturer's instructions for fixed tissues. PCR amplification (Qiagen) was performed, using primers covering the SNP rs7208422 (forward: $5^{\prime}$ ccgtcgcttccagctgat-3'; reverse: 5'-acttggtagcccagaagatgg-3'). Purified PCR products (NucleoSpin Extract II; Macherey-Nagel, Düren, Germany) were subjected to the bidirectional sequencing, using the BigDye Terminator Kit (version 1.1) and ABI Prism 377 sequencer (PE Applied Biosystems) (fig. 10). In patient K.T., the same homozygous genotype as in patient L.H. was found.

\section{Discussion}

Infections with HPV frequently were not recognised and are often clinically unapparent or result in warty lesions like verrucae vulgares or condylomas. In the genital area, depending on sexual behaviour, everybody can get oncogenic $\alpha$-HPV genotypes (e.g. HPV-16 or HPV-18), potentially leading to the evolution of carcinoma in situ or carcinoma of the cervix (or cervical intraepithelial neoplasia) or carcinoma of the penis (or prostatic intraepithelial neoplasia). In contrast EV patients are genetically predisposed to get oncogenic $\beta$-HPV by an abnormal susceptibility to these viruses, mainly to type 5 , but also to types 8,4 , 17,20 and 47 [2]. Half of these patients develop skin cancer [22]. In the unaffected population $\beta$-HPV do not lead to a clinical manifestation because of an intact barrier against the HPV of the beta genus. The susceptibility of EV pa- 
tients is genetically determined and inherited by an autosomal recessive trait [5]. Two responsible genes on chromosome 17q25 have been identified, which were called EVER1/ TMC6 and EVER2/TMC8 [6]. Several loss-of-function mutations have been identified in both genes. These mutations resulted from different mechanisms like nonsense mutations, deletion of exons, splice site mutations or single-nucleotide mutations [2, 6, 16, 21, 23-28]. No EVER1/TMC6 or EVER2/TMC8 mutations have been detected in $25 \%$ of EV patients (including familial cases), revealing the heterogeneity of the disease $[2,29]$. In a case-control study, Patel et al. [20] found that the A-to-T base substitution at the position c.917 in exon 8 of EVER2/TMC8, a SNP (rs7208422), resulting in an amino acid exchange of asparagine for isoleucine, probably has a role in skin carcinogenesis in the general population. The TT homozygous genotype (p.N306I) is assumedly a risk factor for susceptibility to $\beta$-HPV infection and non-melanoma skin cancer $[20,21]$. This homozygous genotype is found in approximately $27 \%$ of the European population [30]. We found a further SNP (rs2748427) in EVER1/TMC6 showing a heterozygous mutation (c.373T $\rightarrow$ C; p.W125R). It remains highly speculative whether the heterozygote polymorphism rs2748427 in EVER1/TMC6 in a patient additionally displaying the homozygote polymorphism rs7208422 in EVER2/TMC8 induces a more defective formation of the whole EVER/ZnT-1 complex than the homozygote polymorphism rs7208422 in EVER2/TMC8 alone. Probably there is another disease-defining mutation on chromosome 2 which we have not yet examined. Nevertheless our findings add some support to the hypothesis that these polymorphisms could somehow influence the susceptibility to $\beta$-HPV and their oncogenic potential. Transcripts of EVER1/TMC6 and EVER2/TMC8 were detected in lymphoblastoid cells and in normal skin [6], and recently published data suggest that EVER1/TMC6 and EVER2/TMC8 are highly expressed in various types of haematopoietic cells [31]. TMC genes encode integral membrane proteins that localise to the endoplasmic reticulum and are predicted to form transmembrane channels. The exact function of these proteins is still unclear, but it is assumed that they belong to a new group of channels or ion transporters and could be involved in signal transduction [7, 8]. EVER1/ TMC6 and EVER2/TMC8 act as modifiers of zinc transporter ZnT-1. Potentially, EVER proteins mediate the protection against oncogenic HPV via regulation of cellular zinc balance $[9,10]$. A mutation in the EVER1 or EVER2 gene might block the formation of the EVER/ZnT-1 complex, which would allow the expression of transcription factors (e.g. AP-1), thus promoting viral replication [32].

\section{Conclusion}

In EV patients there is a strong association between $\beta-H P V$ infection and non-melanoma skin cancer. This predisposition is genetically determined by mutations of the 2 genes EVER1/TMC6 and EVER2/TMC8. However, only in $75 \%$ of EV patients, an EVER mutation has been found. This suggests other genes are involved. A second EV susceptibility locus on chromosome 2p21-p24 by autosomal recessive inheritance is assumed [5]. X-linked recessive inheritance [33] and autosomal dominant transmission have been reported [34]. Further gene identification associated with EV could reveal new insights into host defence against HPV and, thereafter, HPV-associated carcinogenesis. Besides UV light there are other possible additional risk factors such as immunosuppression, HIV infection, lymphoma and graft-versus-host disease [21, 35-39]. Probably these states of immunosuppression and the UV irradiation exhibit a second hit for the development of skin carcinomas in patients with the EVER mutation. Recently, EV-like syndrome has been described in patients with impaired cell-mediated immunity, and the term of 'acquired EV' has been introduced [40].

In our patients we demonstrated the TT genotype (SNP rs7208422) in the EVER2/TMC8 gene as well as a further heterozygous SNP (rs2748427) in EVER1/TMC6, which very likely makes patients vulnerable to oncogenic $\beta$-HPV such as HPV-5 and HPV-8. There is no absolute proof that these polymorphisms cause the clinical signs of EV in our 2 patients. However it supports a possible role of rs7208422 in skin carcinogenesis. The mutated gene which is responsible for the disease in our patients remains to be definitively identified. It is probably located on chromosome 2 , which still has to be analysed.

We have followed until today one of the first patients described with EV, diagnosed by Wilhelm Lutz in Basel already in 1930. L.H. is probably the oldest living subject with this disease. This is a historically and scientifically interesting subject. The story began in Basel with the observation of 4 patients, having led to a helpful explanation of skin carcinogenesis [32].

\section{Disclosure Statement}

The authors declare no conflict of interest and no financial interest.

Polymorphism in EVER2/TMC8 and 


\section{References}

$>1$ Itin PH, Lautenschlager S: Genodermatosis with reticulate, patchy and mottled pigmentation of the neck: a clue to rare dermatologic disorders. Dermatology 1998;197:281-290.

-2 Orth G: Genetics of epidermodysplasia verruciformis: insights into host defense against papillomaviruses. Semin Immunol 2006;18: 362-374.

$>3$ Storey A: Papillomaviruses: death-defying acts in skin cancer. Trends Mol Med 2002;8: 417-421.

$\checkmark 4$ Lutzner MA: Epidermodysplasia verruciformis: an autosomal recessive disease characterized by viral warts and skin cancer - a model for viral oncogenesis. Bull Cancer 1978;65:169-182.

$>5$ Ramoz N, Taieb A, Rueda LA, Montoya LS, Bouadjar B, Favre M, Orth G: Evidence for a nonallelic heterogeneity of epidermodysplasia verruciformis with two susceptibility loci mapped to chromosome regions 2 p21-p24 and 17q25. J Invest Dermatol 2000;114:11481153.

6 Ramoz N, Rueda LA, Bouadjar B, Montoya LS, Orth G, Favre M: Mutations in two adjacent novel genes are associated with epidermodysplasia verruciformis. Nat Genet 2002; 32:579-581.

$>7$ Keresztes G, Mutai H, Heller S: TMC and EVER genes belong to a larger novel family, the TMC gene family encoding transmembrane proteins. BMC Genomics 2003;4:24.

$>8$ Kurima K, Yang Y, Sorber K, Griffith AJ: Characterization of the transmembrane channel-like (TMC) gene family: functional clues from hearing loss and epidermodysplasia verruciformis. Genomics 2003;82:300308.

-9 Lazarczyk M, Favre M: Role of $\mathrm{Zn}^{2+}$ ions in host-virus interactions. J Virol 2008;82: 11486-11494.

10 Lazarczyk M, Pons C, Mendoza JA, Cassonnet P, Jacob Y, Favre M: Regulation of cellular zinc balance as a potential mechanism of EVER-mediated protection against pathogenesis by cutaneous oncogenic human papillomaviruses. J Exp Med 2008;205:35-42.

11 Lewandowsky F, Lutz W: Ein Fall einer bisher nicht beschriebenen Hauterkrankung (Epidermodysplasia verruciformis). Arch Dermatol Syph 1922;141:193-203.

$>12$ Fuchs H: Ein Fall von eigenartiger Dyskeratose (Epidermodysplasia verruciformis). Arch Dermatol Syph 1922;141:225-231.

13 Lutz W: A propos de l'epidermodysplasie verruciforme. Dermatologica 1946;92:3043.

14 Häusermann P, Lutter S, Meigel W, Rufli T: Das Lewandowsky-Lutz-Syndrom: Die Erstbeschreibung und drei weitere Basler Fälle der Epidermodysplasia verruciformis. Z Hautkr 2002;77:176-180.

15 Jablonska S, Milewski B: Zur Kenntnis der Epidermodysplasia verruciformis Lewandowsky-Lutz. Dermatologica 1957;115:1-22.
16 Berthelot C, Dickerson MC, Rady P, He Q, Niroomand F, Tyring SK, Pandya AG: Treatment of a patient with epidermodysplasia verruciformis carrying a novel EVER2 mutation with imiquimod. J Am Acad Dermatol 2007;56:882-886.

17 Bauer HM, Ting Y, Greer CE, Chambers JC, Tashiro CJ, Chimera J, Reingold A, Manos MM: Genital human papillomavirus infection in female university students as determined by a PCR-based method. JAMA 1991; 265:472-477.

18 Husnjak K, Grce M, Magdic L, Pavelic K: Comparison of five different polymerase chain reaction methods for detection of human papillomavirus in cervical cell specimens. J Virol Methods 2000;88:125-134.

19 Harwood CA, Spink PJ, Surentheran T, Leigh IM, de Villiers EM, McGregor JM, Proby CM, Breuer J: Degenerate and nested PCR: a highly sensitive and specific method for detection of human papillomavirus infection in cutaneous warts. J Clin Microbiol 1999;37:3545-3555.

20 Patel AS, Karagas MR, Pawlita M, Waterboer T, Nelson HH: Cutaneous human papillomavirus infection, the EVER2 gene and incidence of squamous cell carcinoma: a casecontrol study. Int J Cancer 2008;122:23772379.

21 Hohenstein E, Rady PL, Hergersberg M, Huber AR, Tyring SK, Bregenzer T, Streit M, Itin $P$ : Epidermodysplasia verruciformis in a HIV-positive patient homozygous for the c917A $\rightarrow$ T polymorphism in the TMC8/ EVER2 gene. Dermatology 2009;218:114118.

22 Jablonska S, Dabrowski J, Jakubowicz K: Epidermodysplasia verruciformis as a model in studies on the role of papovaviruses in oncogenesis. Cancer Res 1972;32:583-589.

23 Donfack J, Buchinsky FJ, Derkay CS, Steinberg BM, Choi SS, Conley SF, Meyer CM 3rd, McClay JE, Campisi P, Hu FZ, Preston RA, Abramson AL, Ehrlich GD, Post JC: Four mutations in epidermodysplasia verruciformis 1 (EVER1) gene are not contributors to susceptibility in RRP. Int J Pediatr Otorhinolaryngol 2006;70:1235-1240.

24 Gober MD, Rady PL, He Q, Tucker SB, Tyring SK, Gaspari AA: Novel homozygous frameshift mutation of EVER1 gene in an epidermodysplasia verruciformis patient. J Invest Dermatol 2007;127:817-820.

25 Aochi S, Nakanishi G, Suzuki N, Setsu N, Suzuki D, Aya K, Iwatsuki K: A novel homozygous mutation of the EVER1/TMC6 gene in a Japanese patient with epidermodysplasia verruciformis. Br J Dermatol 2007;157:12651266.

26 Zuo YG, Ma D, Zhang Y, Qiao J, Wang B: Identification of a novel mutation and a genetic polymorphism of EVER1 gene in two families with epidermodysplasia verruciformis. J Dermatol Sci 2006;44:153-159.
27 Tate G, Suzuki T, Kishimoto K, Mitsuya T: Novel mutations of EVER1/TMC6 gene in a Japanese patient with epidermodysplasia verruciformis. J Hum Genet 2004;49:223225

28 Sun XK, Chen JF, Xu AE: A homozygous nonsense mutation in the EVER2 gene leads to epidermodysplasia verruciformis. Clin Exp Dermatol 2005;30:573-574.

29 Orth G: Host defenses against human papillomaviruses: lessons from epidermodysplasia verruciformis. Curr Top Microbiol Immunol 2008;321:59-83.

30 http://www.ncbi.nlm.nih.gov/SNP/snp_ref. cgi? rs $=7208422$.

31 Su AI, Wiltshire T, Batalov S, Lapp H, Ching KA, Block D, Zhang J, Soden R, Hayakawa M, Kreiman G, Cooke MP, Walker JR, Hogenesch JB: A gene atlas of the mouse and human protein-encoding transcriptomes. Proc Natl Acad Sci USA 2004;101:6062-6067.

32 Lazarczyk M, Cassonnet P, Pons C, Jacob Y, Favre M: The EVER proteins as a natural barrier against papillomaviruses: a new insight into the pathogenesis of human papillomavirus infections. Microbiol Mol Biol Rev 2009;73:348-370.

33 Androphy EJ, Dvoretzky I, Lowy DR: Xlinked inheritance of epidermodysplasia verruciformis: genetic and virologic studies of a kindred. Arch Dermatol 1985;121:864868.

34 McDermott DF, Gammon B, Snijders PJ, Mbata I, Phifer B, Howland Hartley A, Lee CC, Murphy PM, Hwang ST: Autosomal dominant epidermodysplasia verruciformis lacking a known EVER1 or EVER2 mutation. Pediatr Dermatol 2009;26:306-310.

35 Tanigaki T, Kanda R, Sato K: Epidermodysplasia verruciformis (L-L, 1922) in a patient with systemic lupus erythematosus. Arch Dermatol Res 1986;278:247-248.

36 Gross G, Ellinger K, Roussaki A, Fuchs PG, Peter $\mathrm{HH}$, Pfister $\mathrm{H}$ : Epidermodysplasia verruciformis in a patient with Hodgkin's disease: characterization of a new papillomavirus type and interferon treatment. J Invest Dermatol 1988;91:43-48.

-37 Barr BB, Benton EC, McLaren K, Bunney MH, Smith IW, Blessing K, Hunter JA: Papillomavirus infection and skin cancer in renal allograft recipients. Lancet 1989;ii:224-225.

-38 Hultgren TL, Srinivasan SK, DiMaio DJ: Epidermodysplasia verruciformis occurring in a patient with human immunodeficiency virus: a case report. Cutis 2007;79:307-311.

39 Lutzner M, Croissant O, Ducasse MF, Kreis $\mathrm{H}$, Crosnier J, Orth G: A potentially oncogenic human papillomavirus (HPV-5) found in two renal allograft recipients. J Invest Dermatol 1980;75:353-356.

40 Rogers HD, Macgregor JL, Nord KM, Tyring S, Rady P, Engler DE, Grossman ME: Acquired epidermodysplasia verruciformis. J Am Acad Dermatol 2009;60:315-320. 